\title{
Entrevistas a familias
}

\section{Presidente en funciones de la Confederación d'AMPA del País Valencià Gonzalo Anaya (formada por las tres federaciones territoriales del País Valencià), 53 años, Valencia}

\section{Describe brevemente las características de la FAMPA que presides. Indica cuánto tiem- po llevas vinculado a esta Federación, así como tu relación con el ámbito educativo} Se trata de la Confederación de AMPA mayoritaria en Valencia, compuesta por las tres federaciones territoriales del País Valenciano: FAMPA-Valencia, FAMPA-Penyagolosa y FAMPA-Enric Valor. Tenemos casi 1100 AMPA federadas entre las tres. La Confederación hace una labor de apoyo y unión de las federaciones. Entre sus tareas destacan la relación y reivindicación a nivel autonómico con la administración: Consejerías, Generalitat... Elige representantes en la Mesa de Madres y Padres (MMP) y al Consejo Escolar del País Valenciano (CEPV). También tiene un carácter de ayuda a la formación de las AMPA a través de las federaciones. Participa en la emisión de dictámenes y propuestas en las leyes educativas. Asimismo, hace una tarea de reclamación y divulgación a través de los medios de comunicación.

Llevo vinculado al mundo de las AMPA desde que mi hija, Ariadna, entró con tres años en Infantil, en 2009, este año hace 11 años. A nivel orgánico, entré a formar parte de la comisión ejecutiva de la Federación a la que pertenece el AMPA del centro en el que estudian mis hijos Ausiàs y Ariadna (CEIP Juan de Ribera de Burjassot), en febrero de 2014 y, pronto también a la Junta Directiva de la Confederación. Llevo, por tanto, más de seis años vinculado. También soy representante en la Confederación Estatal CEAPA y he pertenecido a su Junta Directiva como vocal autonómico, tres cursos, del 2016 al 2019. Soy miembro del Consejo Escolar Municipal (CEM) de Burjassot desde el año 2013, del CEPV desde el 2014, cuatro años de la Mesa de Madres y Padres (MMP) hasta el año pasado y tres años del Consejo Escolar de estado mientras he sido miembro de la Junta Directiva de la CEAPA.

Aparte de esta vinculación como padre de alumnos, tengo otra. Soy doctor en Física Teórica y profesor universitario. He impartido clases de física desde 1990 hasta 1995 en la Universitat de València, en la que me doctoré. Desde entonces hasta el día de hoy doy matemáticas en el Departamento de Matemática Aplicada de la Universidad Politécnica de Valencia, donde actualmente, y desde 2003, soy Catedrático de Escuela Universitaria. 
Explica brevemente cuáles son los cambios principales que, a tu juicio, ha generado la suspensión de la asistencia a clases presenciales, especialmente para las familias.

La suspensión de las clases presenciales ha supuesto un cambio total. Entre éstos, la adaptación a un modelo totalmente diferente de docencia por parte del profesorado y de aprendizaje por parte del alumnado. Para las familias, también, dado que somos los padres y las madres quienes hemos de dirigir todo el trabajo a partir de la información que recibimos del profesorado. Esto ha acentuado la brecha entre el alumnado porque depende en gran medida de los recursos de las familias. También entre el de la concertada y la pública. La primera, al tener ingresos de nuestros impuestos y propios tiene más posibilidades de atención al alumnado, aparte de que estaba más preparada para la docencia virtual.

Cómo crees que se ha llevado a cabo el proceso de adaptación a esta nueva situación, por parte de la comunidad educativa y especialmente por parte de las familias. ¿Destacarías alguna cuestión significativa en este proceso?

En general se está llevando relativamente bien. Tanto la administración como el profesorado está respondiendo con todo lo que tiene a su alcance y se cubre todo lo que se puede, que es mucho. Las familias están poniendo todo su esfuerzo y empeño.

Una cuestión que quiero enfatizar es que hay alrededor de un $20 \%$ de familias que no disponen de ordenador o de conexión a internet. Esta cuestión es imprescindible para poder seguir la enseñanza no presencial. Aparte, aún las familias que tienen, algunas necesitan el ordenador por el teletrabajo de la madre y/o el padre, o bien, algunos progenitores han de desplazarse al lugar de trabajo, como el personal sanitario o el de ventas básicas. Esto dificulta el aprendizaje a este alumnado. También está la cuestión de la formación de las madres y los padres, un porcentaje no despreciable no puede acompañar al alumnado en sus tareas. Todas estas cuestiones hacen que esta brecha ya existente de por sí aumente. Hay un problema de falta de igualdad y equidad.

Para precisar un poco más, te pedimos que respondas a las siguientes cuestiones, relativas a la gestión cotidiana de las tareas escolares en el contexto que supone la pandemia:

Qué noticias te llegan acerca de la interacción de los miembros de la familia (padres, madres) a la hora de acompañar a los hijos en sus tareas escolares, si necesitan su ayuda, si pueden ayudarles con los conocimientos que tienen, dificultades encontradas, etc.

FAMPA-Valencia ha realizado una encuesta entre las familias para determinar cómo está funcionando la tele-enseñanza. De los datos que se extraen de esta encuesta el porcentaje de alumnado que necesita mucha ayuda para trabajar en casa es del orden del $67 \%$. Muchas madres y muchos padres no pueden acompañar con los conocimientos, aunque esto no se ha preguntado (pero nos consta por lo que nos están comentando las AMPA). Estas son dificultades importantes unidas al «aislamiento informático» que hemos comentado en 3 .

Aunque en Primaria no se avanza contenido, es necesario un seguimiento desde las familias, que es diferente según sea ésta. En Secundaria sí se adelanta, lo que dificulta aún más el acompañamiento de las familias. 
Conselleria ha puesto recursos para paliar esta situación: vales comedores para el alumnado que tiene beca de comedor (una buena alimentación también es esencial). Reparto de tablets y conexiones a Internet para el alumnado más necesitado (éstas no llegan a todo el alumnado ni mucho menos, es sobre todo para los de bachiller y últimos cursos de FP).

\section{Indica si las familias piensan que esta forma de seguir el curso está teniendo algún impacto en el aprendizaje de las hijas e hijos y en qué sentido.}

Sí lo piensan. En el sentido de que no se avanzará en los contenidos y aún habrá lagunas en aquellos que ya se han dado. También se puede ver un impacto positivo en la adaptación y aprendizaje por medios telemáticos.

A tu juicio, desde tu experiencia en la FAMPA que presides y ante esta situación sobrevenida, comenta brevemente cuál es la principal preocupación de las familias y de las AMPA en estos momentos.

La principal preocupación es el logro curricular y la evaluación.

Qué destacarías a la hora de llevar a cabo el cometido de las AMPA ante la pandemia que nos aqueja (dificultades, oportunidades, iniciativas...).

Las AMPA han canalizado a través de las Federaciones sus reivindicaciones. Además, se ha producido un movimiento solidario mediante las AMPA para dar apoyo a todas las familias de cada centro a través de todos los medios disponibles: WhatsApp, Telegram, videoconferencias, llamadas telefónicas, compartir Wifi incluso. Esto en cada una de las clases, a fin de llegar a todo el alumnado y ayudar en las tareas que tienen. Esta ayuda está coordinada con las direcciones y el profesorado.

Las AMPA también están llevando iniciativas solidarias con el resto de la sociedad y la gente trabajadora, la que está sufriendo más dificultades y la que está trabajando para cuidar de todos nosotros.

¿Señalarías algún tipo de cambio significativo en la relación entre el profesorado y las familias producido por la actual situación?

Se ha mejorado la red de comunicación, interacción y coordinación.

Indica si se ha puesto en marcha algún proceso de formación u orientación a las familias ante el cambio producido por el paso de la docencia presencial a la docencia en línea. Si es así, realiza alguna valoración sobre esta experiencia.

Conselleria ha sacado toda una serie de manuales y material de tutorías por las redes. También el profesorado realiza cierta formación.

Respecto de las AMPA, existía formación presencial que impartían las federaciones sobre la docencia en línea. Se ha colgado el material de esta formación. Desde las federaciones se orienta en este sentido y las AMPA han establecido la red de apoyo que he comentado en 6.

No es posible hacer una valoración todavía de esta formación. 
Señala si crees que está teniendo algún impacto en términos de igualdad o desigualdad para las familias y para el alumnado y, en caso afirmativo, en qué sentido.

Está teniendo un impacto de desigualdad muy grande. Las razones, las aducidas anteriormente. La desigualdad por la formación académica de las madres y los padres tan diversa. La desigualdad por la disparidad de los medios telemáticos, incluso de la inexistencia. La desigualdad por las condiciones socioeconómicas. La desigualdad producida en el caso de que la madre y/o el padre trabajan telemáticamente y más si lo hacen de manera presencial, al no encontrarse en casa mucho tiempo.

Cuáles son las principales conclusiones que extraes de esta experiencia educativa y qué aprendizaje extraes de esta experiencia de cara al futuro.

Hay que avanzar en el aprendizaje en línea. Hay que proporcionar a todas las familias los medios telemáticos necesarios: esta acción se puede realizar mediante ayudas de la administración y la concienciación a todas las familias que son necesarios por sus hijos y sus hijas.

Otro aprendizaje es que la educación en valores es más que nunca necesaria. Los niños y niñas están aprendiendo estos valores a partir de vivir la gran red de solidaridad social que se está generando en torno a la situación. Evidentemente, con una sociedad diferente donde lo primero que contara fueran las personas y no las mercancías el impacto sería mucho menor.

Te pedimos también que valores las consecuencias y el impacto educativo y social de esta crisis a corto y medio plazo, una vez que se supere la situación.

Por un lado, el empobrecimiento de las personas y la brecha social que se ha acentuado. Muchas personas han dejado de trabajar. También en muchas casas se ha dejado de tener ingresos. Por otra parte, aprenderemos que se puede pasar con mucho menos, que la solidaridad y el reparto social y económico se hace más que nunca necesario así como el cuidado del planeta. La importancia de disponer de un sistema público fuerte con todos los recursos, tanto a nivel sanitario, como educativo y de servicios sociales.

Finalmente, nos gustaría preguntarte por alguna otra cuestión, comentario, sugerencia, que quieras hacer para terminar.

Por último, una de las enseñanzas para toda la sociedad sería que es necesario un cambio total de sistema socioeconómico tanto para preservar el planeta y la humanidad como para que toda la clase obrera y el pueblo trabajador tengamos lo necesario que, por otra parte, se está demostrando que es mucho menos de lo que nos quiere vender este sistema capitalista explotador y devorador de las personas en el que vivimos.

Gracias por tu colaboración.

Un placer haber contribuido al análisis y el cambio social. A vosotros también agradeceros por haber contado con el movimiento de las AMPA. 


\section{Mónica Calvo Castro, madre y enfermera, 42 años, Granada}

Indica, por favor, cuántos miembros estáis conviviendo en casa en este momento de confinamiento, edad de cada miembro, nivel educativo de cada miembro y a qué se dedica, con especial atención a si se está en casa o tiene un empleo que le obliga a salir en este momento.

En casa somos 4 miembros:

Mi hijo de 6 años, cursa $1^{\circ}$ primaria.

Mi hija de 2 años, no iba a guardería en el momento del confinamiento.

Mi marido de 43 años, es licenciado universitario y trabaja como autónomo, se encuentra en casa desde el confinamiento por cese de su actividad laboral.

Yo tengo 42 años, soy diplomada universitaria y enfermera en activo de la UCI pediátrica del Hospital Materno Infantil de Granada.

Explica brevemente cómo se distribuyen las labores del hogar entre sus miembros durante el confinamiento: tareas que se han realizado en el hogar durante la última semana y duración (aproximada) de cada tarea, así como miembro del hogar que la ha realizado. Señala también si ha cambiado esa distribución de tareas entre los miembros del hogar en relación a antes del confinamiento.

Depende de si yo tengo que trabajar o tengo días libres en casa.

Cuando yo trabajo mi marido se encarga de las tareas domésticas: hacer la comida, limpiar, fregar, hacer las actividades escolares con el niño, bañar a los niños.

Los días que tengo descansos yo me encargo de hacer la comida, poner la lavadora, planchar, hacer las camas y organizar ropa.

Mi marido se encarga de ayudar al niño con las actividades escolares, poner y quitar la mesa y fregar los platos.

Entre los dos nos encargamos de la limpieza de casa, el aseo de los niños, dar de comer a los niños.

Con respecto a la realización del trabajo escolar (deberes) de tus hija.o.s durante el confinamiento, te pedimos, por favor, que respondas a las siguientes preguntas:

De qué medios tecnológicos dispones en casa (un ordenador, varios ordenadores, una tablet, un móvil inteligente, ninguno de éstos) para hacer el seguimiento virtual de tu deberes.

En casa disponemos de un ordenador, una tablet y dos móviles. Las actividades escolares nos las pasa el profesor a través de la plataforma del colegio, y el niño las realiza en sus libros y libretas. Los videos educativos los visualizamos en el móvil o en la televisión.

Cómo es la conexión a internet que tenéis en tu casa (Tipo de conexión -4G, Fibra, Rural...-, Velocidad).

Tenemos Fibra de 200 megas. 
Qué se está haciendo desde el centro educativo, por qué vía os llegan los deberes, cómo es la interacción con el tutor.a de tu.s hijo.a.s y con el resto del profesorado (si los hubiere), cómo es la interacción tuya y de tu pareja con tu hijo.a.s a la hora de hacer los deberes, si necesitan tu ayuda, si puedes ayudarles con los conocimientos que tienes, cómo se corrigen los ejercicios, cómo se está planteando la evaluación del $2^{\circ}$ trimestre.

Los deberes nos llegan a través de la plataforma del colegio en un archivo de Google Drive; en la clase se utiliza desde este año la aplicación Class Dojo y ahí podemos consultar al profesor las dudas que nos surjan.

Tanto su padre como yo estamos muy implicados en la realización de las tareas, los dos le ayudamos a realizarlas, su padre dedica más tiempo que yo, al ser primero de primaria le podemos ayudar con nuestros conocimientos sin problema. Los ejercicios al hacerse en sus libros y libreta no hay forma de que el profesor los corrija, se habló que cuando se volviera a clase los examinaría para ver que los llevan realizados. Las notas de evaluación del $2^{\circ}$ trimestre se colgaron en Pasen el día 27 de marzo, la $2^{\mathrm{a}}$ evaluación terminaba el 19 de marzo en Primaria.

Después de Semana Santa empezamos a enviar trabajos para ir haciéndoles evaluación en la plataforma de Class Dojo que es la que usamos.

Qué horario ocupan los estudios y su realización a lo largo del día, qué tipo de actividades implican, cómo es esa rutina diaria

Las actividades escolares las realizamos por la mañana, normalmente de 10:30 a 13:30, con un descanso como en el cole.

Empezamos por la lectura del libro de clase y actividades, después hacemos unas páginas del libro de lengua y un dictado; seguimos con matemáticas, ejercicios del libro de mates, ejercicios en la libreta, actividades prácticas usando materiales de casa; ejercicios de inglés, que suelen ser visualización de algún vídeo; actividades del libro de ciencias sociales; actividades del libro de ciencias naturales; y un día en semana tenemos actividades de música, visualización de algún vídeo, y actividades de religión, algún ejercicio práctico o manualidad.

De todas formas las actividades varían en función del día y la asignatura, nosotros recibimos la planificación de forma semanal.

Indica si crees que esta forma de seguir el curso está teniendo algún impacto en el aprendizaje de tu.s hijo.a.s y en qué sentido.

Yo pienso que aunque nos ocupa tiempo a los padres, al ser una atención personalizada al niño le esta viniendo bastante bien, lo vemos más suelto en lectura y en escritura, sin duda está siendo positivo.

Señala las dificultades que encuentras a la hora de hacer realizar los deberes de esta manera.

La principal dificultad es la distracción que supone tener a la hermana alrededor a la hora de hacer los ejercicios. 


\section{Cuáles son las principales conclusiones que extraes de esta experiencia educativa.}

Aunque cuesta trabajo que el niño arranque con las actividades diarias pensamos que le está viniendo muy bien que los padres estamos pendientes de cómo hace los ejercicios y de resolverle las dudas y animarlo.

Señala si crees que está teniendo algún impacto en términos de igualdad o desigualdad para el alumnado y, en caso afirmativo, en qué sentido.

El tema más problemático que veo es si los dos padres se encuentran trabajando, ahí sí que entre la carga laboral y las actividades de los niños la situación puede complicarse, o si se tienen varios hijos a los que ayudar.

Ahora te pedimos que hagas un breve balance de esta experiencia de confinamiento y de teletrabajo educativo en relación a las siguientes cuestiones:

Principales debilidades y dificultades, situaciones de estrés, de conflicto entre los miembros del hogar.

Se hace duro el no poder salir a la calle para dar un paseo con los críos, nuestro niño tenía actividades extraescolares y al no adaptarse a la modalidad online las hemos suspendido; el estar tanto tiempo juntos y la sucesión de malas noticias genera tensiones y pequeñas riñas domésticas, mucha tensión acumulada; en el hospital se están pasando momentos muy difíciles y aunque se intenta desconectar en casa a veces es difícil.

Aspectos positivos, algo que puedas extraer como una ventaja en medio de esta situación compleja, alguna reflexión en términos de crecimiento personal.

Quizá le estoy dando más importancia a la familia, a que lo más grande que tenemos es volver a casa con los nuestros y sin duda creo que aprenderemos a relativizar los problemas a partir de ahora.

\section{Y en términos emocionales, afectivos y personales, ¿̇cómo lo estás viviendo? ¿̇cómo lo estás gestionando?}

Por ahora lo llevo bien, el ánimo está decaído y el ambiente en el trabajo es duro, pero la ventaja que tenemos los que somos padres es que al llegar a casa nos reciben los niños, y es imposible tener un momento de descanso con su energía infinita, su alegría y su inocencia, te dejan pensar poco.

\section{Qué aprendizaje extraes de esta experiencia de cara al futuro.}

Que hay situaciones que nunca nos imaginaríamos que iban a pasarnos a nosotros, a un país del primer mundo, y que el ser humano se adapta a estas situaciones para salir reforzado y más unido que nunca.

Te pedimos también que valores las consecuencias y el impacto educativo y social de esta crisis a corto y medio plazo, una vez que se supere la situación.

Supongo que a nivel de $1^{\circ}$ de primaria el impacto tampoco será tan decisivo como en ciclos superiores, pienso que aunque no diesen más clase en lo que queda de curso, el año que viene se engancharían sin problema al siguiente curso.

Finalmente, nos gustaría preguntarte por alguna otra cuestión, comentario, sugerencia, que quieras hacer para terminar.

Ojalá todo esto sirva para hacernos mejores personas y para tomar todas las precauciones necesarias para que no se vuelva a repetir. 